\title{
SIMULAÇÃO DAS CIRCULAÇÕES LOCAIS NO RIO GRANDE DO SUL: FORMAÇÃO E INTERAÇÃO DAS BRISAS NO INTERIOR E
}

\author{
REGIÃO COSTEIRA DO ESTADO \\ Maikel R. S. Gambetá Leite ${ }^{1,2}$, Nisia Krusche ${ }^{1}$ \\ ${ }^{1}$ FURG - Universidade Federal do Rio Grande - Rio Grande - Rio Grande do Sul \\ ${ }^{2}$ maikel.leite@ furg.br
}

\section{RESUMO}

Foi utilizado um modelo numérico de mesoscala para realizar uma simulação idealizada das circulações locais no Rio Grande do Sul. Os resultados mostram a formação da brisa em diferentes períodos para duas localidades distintas, devido a conformação do relevo. A partir da análise das células de circulação, observou-se a formação de um tipo de brisa nas proximidades de Santa Maria e Bagé e três tipos de brisa na região costeira.

\section{ABSTRACT}

We investigated, using a mesoscale numerical model, the structure and evolution of the local circulation in Rio Grande do Sul on March, 16th to 18th, 2012. Local circulations such as the sea breeze, lake breeze and the brezze due to the complex terrain occur at different times. The analysis of circulation cells indicates differences and interactions between them.

\section{INTRODUÇÃO}

O Rio Grande do Sul está em localização favorável à formação de tipos de brisa bem caracterizados devido a formação do relevo e a sua proximidade com os sistemas lacustres e também o Oceano Atlântico, que contornam a localidade. Estas podem ser marítimas, lacustres e terrestres e são caracterizadas pelo gradiente de pressão e temperatura gerado pelo aquecimento desigual entre terra e água (Atkinson, 1981). Já a brisa de vale-montanha ocorre devido ao aquecimento diferenciado entre as regiões superiores e inferiores da mesma (Mahrer and Pielke, 1977). Estes ventos locais tem influência sobre os movimentos das camadas de ar em superfície e podem ser observados a diversos quilômetros de onde foram originados, conforme estudo prévio realizado por Braga e Krusche (1998).

Desta forma, foi realizado um estudo sobre o comportamento dos ventos sobre a região de estudo através de uma simulação sem a influência do vento sinótico utilizando o modelo Weather Research and Forecasting (WRF) para o período entre 16 e 19 de março de 2012.

\section{MATERIAL E MÉTODOS}

Como condições iniciais e de fronteira do modelo WRF, foram utilizados os dados FNL-NCEP, com resolução horizontal de um grau de longitude e de latitude, 27 níveis verticais e resolução temporal de 6 horas. Utilizaram-se duas grades aninhadas, sendo a primeira grade de $9 \mathrm{~km}$ com 100 x 100 pontos e a segunda com $3 \mathrm{~km}$, com 135 x 135 pontos; centradas em -30.03 e -53.15 de latitude e longitude, respectivamente, conforme Figura 1. 
Para a simulação sem o vento sinótico, foi removido o método de interpolação para as variáveis dos dados de entrada das componentes zonal e meridional do vento sinótico (u e v). Desta forma, os dados de entrada do vento sinótico não interagem com os demais fazendo com que a circulação do vento seja definida apenas pelas variáveis de temperatura, topografia e mesoescala.

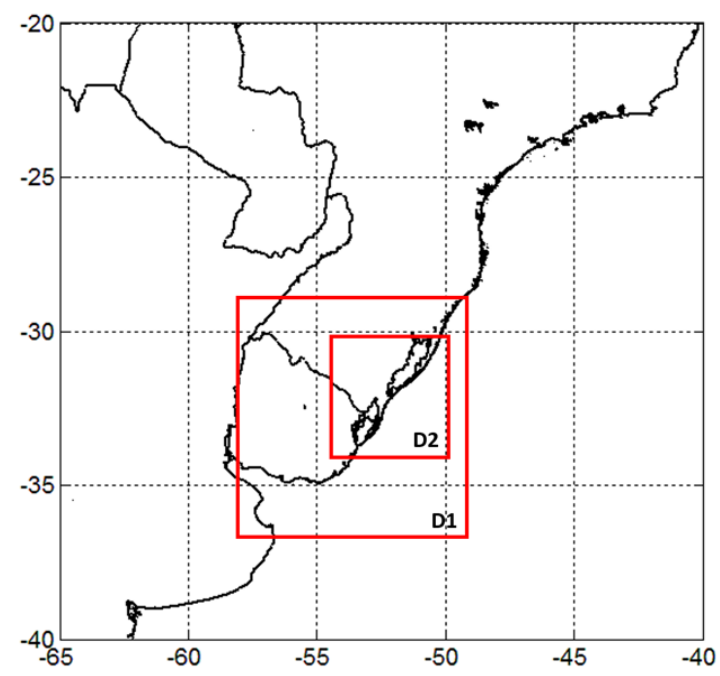

Figura 1 - Região de estudo contendo as grades aninhadas utilizadas para a simulação idealizada com o modelo WRF.

\section{RESULTADOS}

Foram analisados os campos de vento e o perfil vertical através da formação de células de circulação ascendentes e descendentes em dois pontos distintos de acordo com a Figura 2.

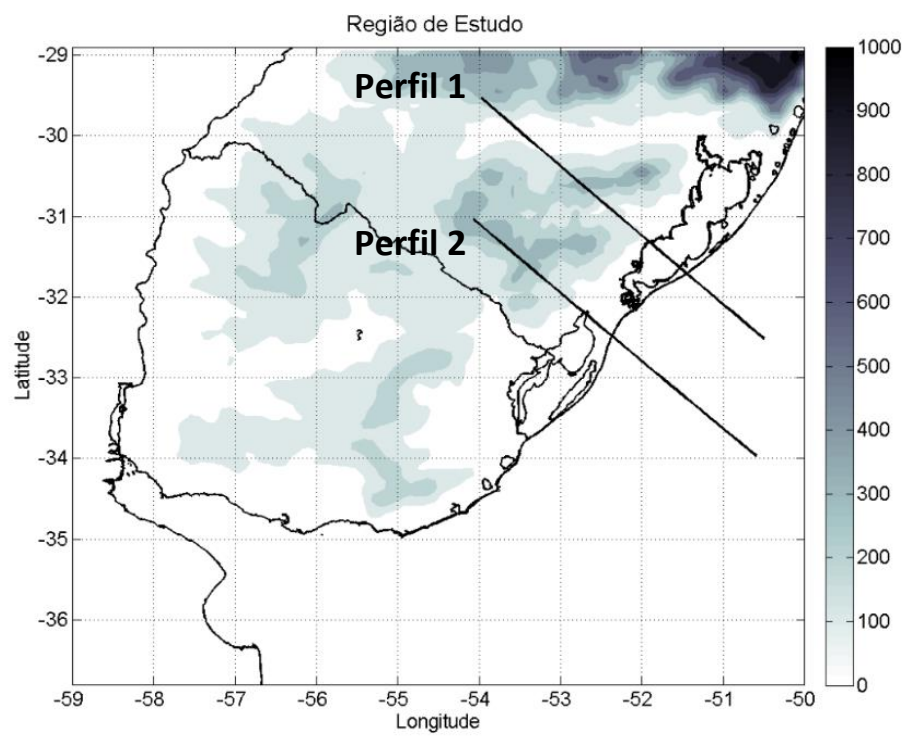

Figura 2 - Topografia da região de estudo contendo os dois cortes escolhidos para a análise das células de circulação ascendentes e descendentes 
A análise da componente vertical do vento permitiu observar a formação das células de circulação, identificar o tipo de brisa e horário em que ocorrem. Às $21 \mathrm{hs} \mathrm{local}$ (HL), registra-se a presença da brisa marítima sobre o oceano e da lacustre sobre a Lagoa dos Patos, caracterizada pelas células de circulação ascendentes, que também podem ser observadas na região mais baixa do relevo próximo a região de Bagé e Santa Maria. A partir das $0 \mathrm{HL}$ do dia dezoito, observou-se a formação da célula descendente na região mais elevada do relevo, assim como em algumas regiões costeiras próximas ao oceano e também Lagoa dos Patos. As células ascendentes movem-se em direção ao oceano entre 3 HL e 6 HL comprovando o efeito da brisa terrestre. Às $9 \mathrm{HL}$, à medida que a radiação solar aquece o continente, células de circulação ascendentes intensificam-se sobre as regiões mais baixas do revelo, próximo a região de Bagé, e também nas proximidades das porções de água e, às 12 HL intensificam-se aumentando sua velocidade. As células ascendentes aumentam em quantidade e intensidade no horário das $15 \mathrm{HL}$ e movimentam-se na direção da Lagoa dos Patos. Nas porções mais elevadas do terreno, a intensidade das células de circulação ascendente é reduzida, praticamente nula quando comparada as outras regiões. Às $18 \mathrm{HL}$ observou-se uma maior intensidade da célula de circulação ascendente próxima a região de Santa Maria, quando comparada a região de Bagé, no entanto esta última apresentou uma maior quantidade de células ascendentes em toda sua extensão.
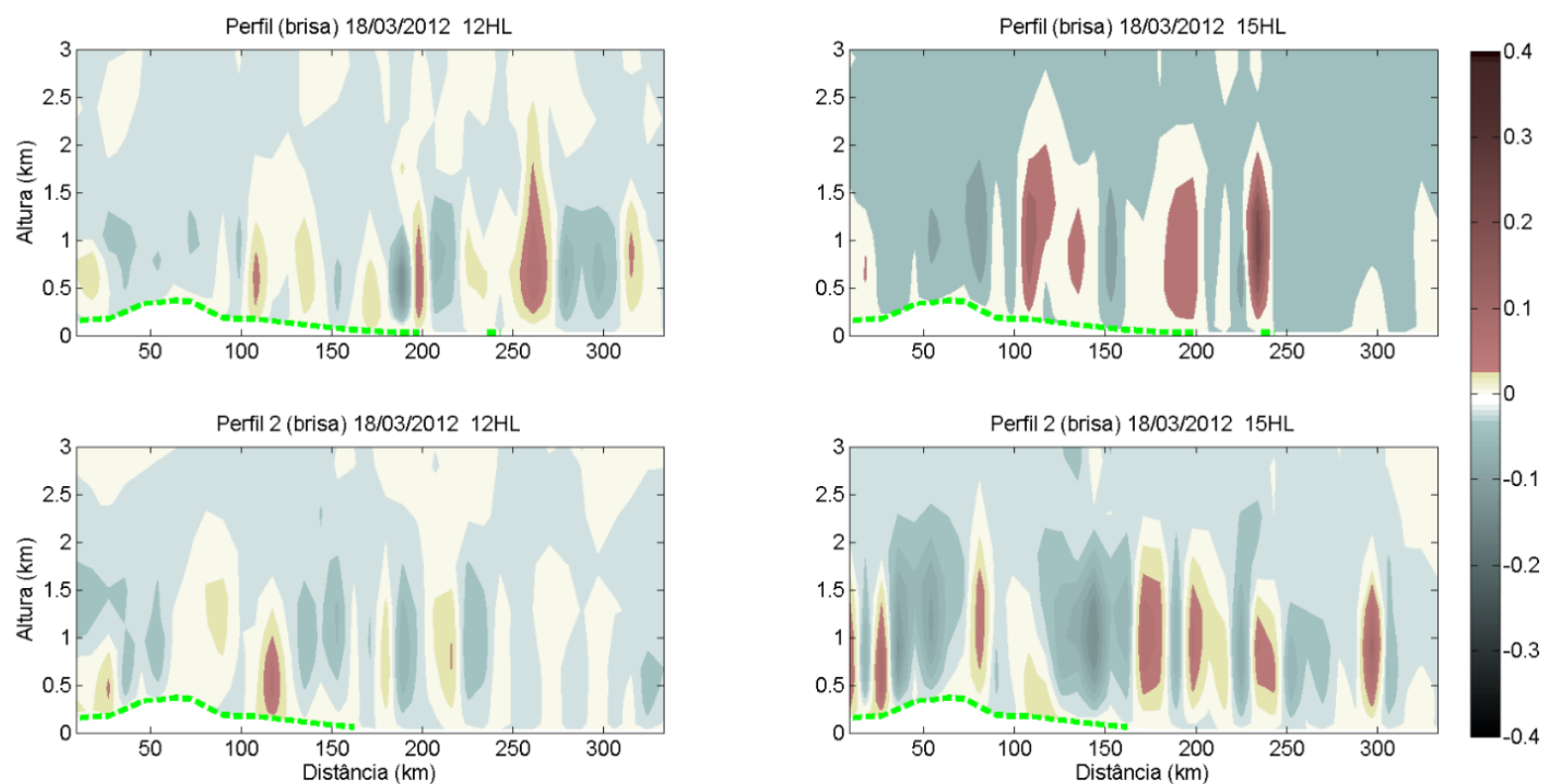

Figura 3 - Perfil vertical com $300 \mathrm{~km}$ de extensão e $3 \mathrm{~km}$ de altura sobre a região do Perfil 1, a) e b), e Perfil 2 para as $12 \mathrm{HL}$ e $15 \mathrm{HL}$, c) e d). A faixa verde representa a topografia da região. 


\section{ciênciaenatura}
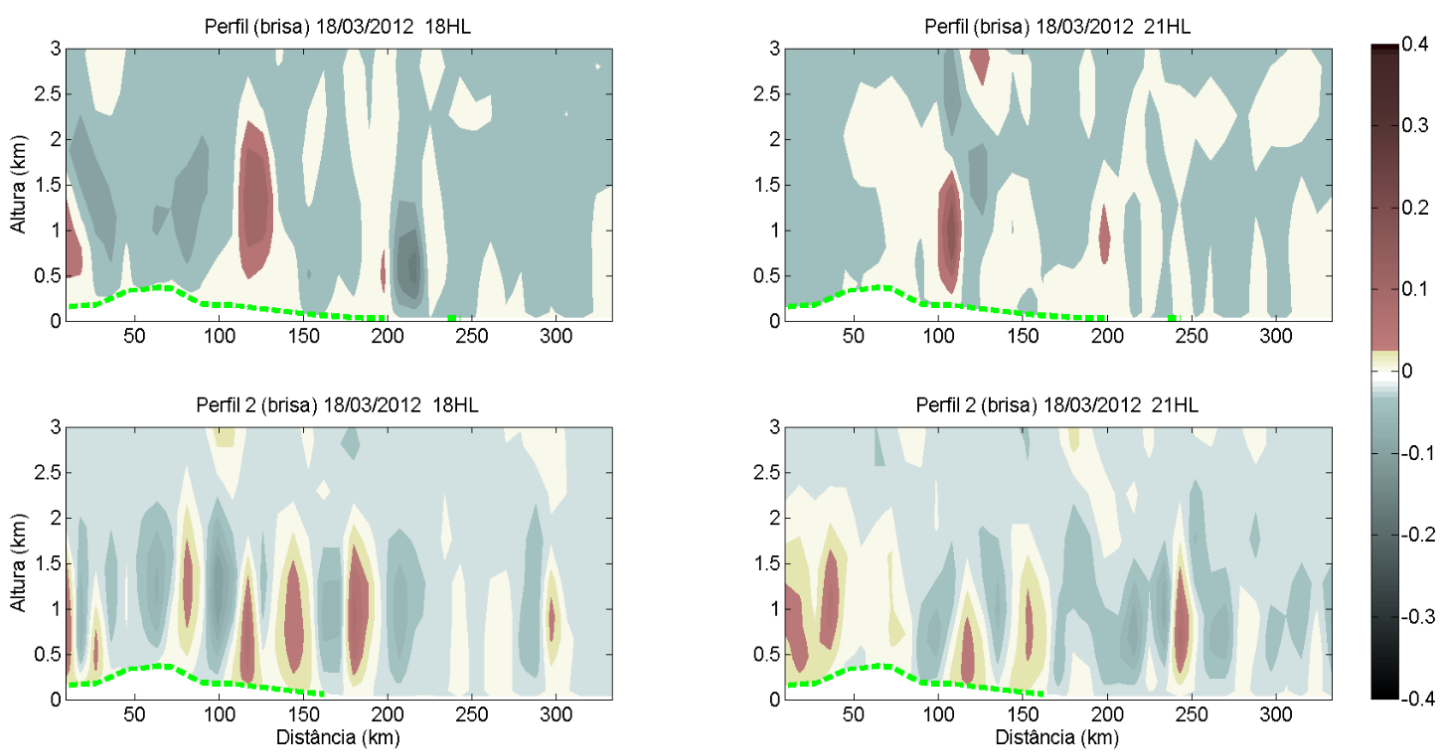

Figura 4 - Perfil vertical com 300 km de extensão e 3 km de altura sobre a região do Perfil 1 e Perfil 2 para as $18 \mathrm{HL}$ e $21 \mathrm{HL}$. A faixa verde representa a topografia da região.

\section{DISCUSSÃO}

Foram observadas a formação das brisas de vale-montanha, marítima, lacustre e terrestre nas regiões analisadas. Os horários de formação da brisa corroboram a análise descrita por Braga e Krusche (1998). A brisa de vale e a brisa marítima e lacustre apresentaram maior intensidade quando comparadas com a brisa terrestre e a brisa de montanha. Houve uma maior interação entre as brisas para o perfil 2 do que para o perfil 1 .

\section{AGRADECIMENTOS}

Agradeço ao Núcleo de Física Ambiental, aos colegas de laboratório à Camila e Silva Gomes e à Rosmeri Porfírio da Rocha pela contribuição ao trabalho.

\section{BIBLIOGRAFIA}

ATKINSON, B. W. Meso-Scale Atmospheric Circulations. Academic Press, London. 1981. p. $125-214$.

BRAGA, M.F.S.; KRUSCHE, N., Análise da Frequência das Velocidades do Vento em Rio Grande, RS, Anais do XI Congresso Brasileiro de Meteorologia, Campos do Jordão, 1998.

Dados de entrada: Disponível em: 〈https://rda.ucar.edu> . Acesso em: 25 março 2012.

MAHRER, Y.; PIELKE R. A., The effects of topography on sea and land breezes in a two dimensional numerical model. Monthly Weather Review, 105, 1151-1162. 1977.

PIELKE, R.A., An overview of our current understanding of the physical interactions between the sea- and land-breeze and the coastal waters.Ocean Management, 6, 87-100. 1981. 